\title{
Long-Term Impacts of Short-Term Study Abroad: Teacher Perceptions of Preservice Study Abroad Experiences
}

\author{
James Shiveley \\ Miami University \\ Thomas Misco \\ Miami University
}

\section{Introduction}

In recent years teacher education programs across the country have worked to increase the focus on global competency among the skills needed for a beginning teacher (Quezada, 2004). For the purposes of this study, global competency is defined as, "a body of knowledge about the world regions, cultures, and global issues, and the skills and dispositions to engage responsibly and effectively in a global environment" (Longview Report, 2009, p. 7). This increased focus has resulted from a heightened understanding that America's youth need to be taught by teachers who are able to "cultivate in young people a perspective of the world, which emphasizes the interconnections among cultures, species, and the planet" (Chapman, Becker, Gilliom \& Tucker, 1982, p.1) and a call from many state departments of education to create initiatives designed to support and increase global education in the K-16 public school system (Asia Society, 2010). Global education within teacher education is increasingly seen as critical if students are to "develop the knowledge, skills, and attitudes that are necessary for decision-making and effective participation in a world characterized by interconnectedness, cultural pluralism, and increasing competition for resources" (Merryfield, 1994, p. 1).

The efforts to incorporate a global dimension into an already crowded teacher education curriculum can be a challenge. Infusing key global concepts into pedagogy courses, requiring courses in the arts and sciences that specifically focus on global themes, requiring projects that promote understanding of race and social justice issues, and including discrete modules and seminars on international education issues and cross-cultural perspectives in the teacher licensure program are all strategies that are being practiced. In addition, many teacher education programs are working to provide study abroad experiences as a critical component of their programs. Indeed, some believe that not to do so is to exclude the most important element of the equation. According to Quezada (2004), providing teaching experiences abroad in the program is "the key ingredient if the United States wants its future teachers to be culturally and globally literate to meet the challenges of this new age" (p. 464). Similarly, the Longview Report (2009) stated that, "interacting first-hand with people from another country or culture is an invaluable component of a good global education" (p. 21). This report went on to say that:

Limited time and resources have traditionally prevented teacher candidates from taking advantage of study abroad, but this is beginning to change as the value of such experiences becomes increasingly evident. Education programs are exploring innovative ways to ensure that their students have international experiences in the course of their teacher preparation. (Longview Report, 2009, p. 21) 
The result is that many study abroad programs designed for teacher candidates last, by necessity, only a few weeks. Research on the effectiveness of such short-term experiences is mixed. Therefore, the purpose of this study was to determine whether or not a short-term study abroad course, taken during preservice teachers' undergraduate program, had any lasting professional or personal impact once they become teachers.

\section{A Review of the Literature}

In order for future teachers to become more sensitive toward, and have a clear understanding of the diverse student populations that they will increasingly find in their classrooms, teacher preparation programs need to include more international and global experiences (Blair, 2002). An increase of global and cross-cultural perspectives can greatly assist teachers in effectively teaching the changing student population in the U.S. and such perspectives may be enhanced through study abroad experiences.

Study abroad experiences have the potential to help beginning teachers better understand other cultures (Quezada, 2004; Stachowski, 2001), gain a greater appreciation for the strengths and weaknesses of their own educational system, and develop the skills, perspectives, and dispositions to incorporate a global dimension into their teaching (Quezada, 2004). As preservice teachers examine their own culture along with previously unquestioned values, they develop a criticality of assumed educational practices, as well as their own biases and prejudices (Stachowski, 2001), hopefully reducing their own dogmatism and developing more open-mindedness toward alternative approaches to education. Opportunities to teach in other countries expose students to different ideas and procedures challenging their ideas that certain teaching strategies or administrative practices are universal. Many student teachers ultimately draw eclectically on the best of both systems (Moseley, Reeder, \& Armstrong, 2008; Quezada, 2004).

Pre-service teachers with study abroad experiences may be better positioned to develop the pedagogical skills to teach their students appreciation of multiple points of view and understanding issues from multiple perspectives (Longview Report, 2009; Moseley, Reeder, \& Armstrong, 2008). By increasing levels of self-evaluation and successfully developing new relationships, students who study abroad often develop a sense of confidence, a stronger value system, and become more confident in their own abilities (Douglas \& Jones-Rikkers, 2001; Hartman \& Rola, 2000; Hopkins, 1999; Laubscher, 1994; Quinn, Barr, Jarchow, Powell, \& Mckay, 1995; Zorn, 1996). Such teachers will better develop the pedagogical skills to teach their students, to appreciate multiple points of view, and to recognize stereotyping, among other valuable skills (Longview Report, 2009). They will also develop the ability to understand issues from multiple perspectives and to be more open-minded and less ethnocentric (Moseley, Reeder, \& Armstrong, 2008).

Additional benefits for teachers to engage in study abroad experiences include the ability to better understand a second language and, in the process, to better teach those students whose first language is one other than English. If the goal is to be better prepared to teach those students who are attempting to learn content in a language other than their native one, then experiencing the cultural roots of others can assist teachers to do this (Blair, 2002). Finally, there is a common belief that international experiences make students more competitive in the job market by promoting career and trade opportunities, increasing "worldmindedness," and improving organizational effectiveness 
(Achterberg, 2002; Cox, 1993; Hopkins, 1999; Kitsantas \& Meyers, 2001; Levy, 2000). It is a long-held assumption that this is the case in the field of business, where educational experiences abroad are valued (Trooboff, Vande Berg, \& Rayman, 2007-2008), but there is also some evidence that suggests that those students who have international experiences have an initial advantage in the hiring process with school hiring administrators (Shiveley \& Misco, 2012).

Even if one accepts that there are tangible benefits for teachers who are globally competent and that a vital factor for preparing such teachers includes a study abroad experience, there remains the question of how best to fit such experiences into the undergraduate curriculum. Most of the recent growth of study abroad experiences at the university level may be linked to the increase in short-term study-abroad experiences lasting less than a semester, many of these coming during summer or intercession terms (Kehl \& Morris, 2008). Yet, how effective are such short-term study abroad experiences in promoting the aforementioned attributes and dispositions? Although there are a paucity of studies that compare the benefits of long-term study abroad experiences to those of short-term ones, there are three empirically based inferences we might consider. The first is that study abroad experiences do have a marked effect on students' global or world mindedness, whether this is defined as gaining knowledge of other cultures or an increased interest in international affairs (Sharma \& Klasek, 1986), a feeling of more connectedness to a global community (Hett, 1993; Deng \& Boatler, 1993), an increased open-mindedness about other cultures (Stephenson, 1999), or an increased level of global perspective (Zhai \& Sheer, 2004). The second is that, not surprisingly, long-term study abroad experiences (i.e., those lasting a semester or longer) have a greater impact on these dispositions than do short-term ones (Kehl \& Morris, 2008, Zorn, 1996; Medina-López-Portillo, 2004). The benefits of long-term experiences notwithstanding, the third inference is that even short-term study abroad trips can also have a lasting impact on preservice teachers and their development of critical and reflective attention to U.S. education within a global context (Dwyer, 2004; Willard-Holt, 2001). Acknowledging that trips of a short duration have the potential of reinforcing prejudices and assumptions with inadequate orientation and cursory involvement in a foreign culture (McKay \& Montgomery, 1995), well-designed short-term experiences have the potential to provide growth in tolerance of ambiguity, increase reflective thinking, stimulate open-mindedness, and prompt selfconfidence (Wilson, 1982; Wilson, 1993). Short-term study abroad experiences may also develop a preservice teacher's worldview, empathy, criticality of own country, comfort navigating unfamiliar contexts, open-mindedness, enhanced global perspectives, and increased professional competence (Malewski \& Phillion, 2009; McKay \& Montgomery, 1995; Pence \& Macgillivray, 2008).

\section{Course Description}

"Comparing U.S. and European Schools" (EDT 455) is a three-credit hour course at Miami University designed for education majors who are entering their final year of study. Miami has offered some variation of EDT 455 for almost 20 years and, over time, this course has developed a reputation as a meaningful and exciting education opportunity that also fulfills a university capstone requirement. Approximately 30-40 students preparing to be teachers take this course each year, participating in lectures and discussions about American and European culture and educational systems before traveling to Europe to observe classrooms and engage with teachers and students in Luxembourg, Austria, and Switzerland. 
The course contains three main components. The first of these occurs during the spring semester prior to the departure for Europe in May. During this semester, the students are required to attend a series of instructional seminars designed to develop the social, cultural, and intellectual background on Europe necessary for visiting the host schools in Europe and to provide students with specific information about the national school systems in of each of the countries the group will visit. The second part of the course consists of travel and study in Europe for three weeks in May when the pre-service teachers conduct classroom observations, attend lectures and panel presentations by European educators, and interact with teachers and students. The pre-service teachers are placed in school settings that are similar to their own majors (e.g., early childhood majors in primary schools, secondary science majors in high school level science classes). These pre-service teachers also visit cultural sites in order to better understand the relationships between European communities and the schools that serve them. The third part of the course occurs during the summer after the students return from their study abroad. At this time all remaining course assignments are completed. All students participating in the comparative education course are evaluated based on their performance in five categories: class participation, field notes and summary reflections, comparative responses to the themes that emerged during the study abroad experience, the completion of a brief application response paper, and a comparative education term paper. The class participation grade is based on attendance and active participation in all pre-travel seminars, appropriate attendance and behavior during the comparative experience and participation in the debriefing session upon returning to the U.S. The comparative education term paper requires students to write an in-depth research-based paper comparing one aspect of U.S. and European schools that emerged over the duration of the course. The application assignment is a one-page reflection that asks students to apply their experiences from the course to some aspect of their future career.

This study sought to understand the durable and residual impacts on pedagogical approaches, curricular decisions, and personal/professional development over time of current teachers who were former participants of this comparative education course.

\section{Methodology}

Given the dynamic nature of our inquiry, in terms of narrative experiences as located within a post-positivistic paradigm of multiple and overlapping realities, we chose to conduct a qualitative case study (Miles \& Huberman, 1994; LeCompte \& Schensul, 1999a). We employed web-based questionnaires, which are extremely useful for understanding a particular problem in an in-depth way (Maxwell, 2010). We worked with our university's development and alumni office in order to access the names of all students, and their respective email addresses, who had taken the comparative education course (EDT 455) within the past 13 years (2000-2013). We received a spreadsheet that included 536 student names, of which 392 included a last known email address. We invited all 392 students to participate, which resulted in 369 valid, non-returned email addresses. We enjoyed a $46 \%$ response rate as 170 former students replied to our invitation and completed the questionnaire. We chose to focus on the 148 respondents who had indicated that they currently teach or have been employed as a teacher since taking the comparative education course. Our sampling strategy was thus typical-case and purposeful (Patton, 1990). Purposeful sampling lacks a rigid formula and instead relies upon criteria such as accessibility, representability, and interest (Toma, 2006). 
In order to maximize the response rate to the questionnaire, we used various techniques that have been known to increase rates. First, we employed the strategy of preliminary notification by emailing respondents in advance (Yammarino, Skinner \& Childers, 1991; Cole, Palmer \& Schwanz 1997; Dillman, 1991; Fox, Crask \& Kim, 1988). We also used less effective but still statistically significant strategies, including a relatively short and straightforward questionnaire format (Cole, Palmer, \& Schwanz, 1997) and university sponsorship (Fox, Crask, \& Kim, 1988). The questionnaire contained twelve basic closed-ended demographic and teaching experience questions (see Appendix A) and four open-ended questions relating to the rationale of the study (e.g., please describe how the course impacted you professionally) (Slavin, 1992). We provided each respondent with a $\$ 10$ Amazon gift voucher as an incentive. Vouchers are the most effective incentive in long questionnaires (30-45 minutes), while lotteries are more efficient in short surveys (15-30 minutes), and "there is no significant difference in response rates between $\$ 5$ or $\$ 20$ prepaid incentives" (Centers for Disease Control and Prevention, 2010; Ruyter, Wetzels, \& Oosterveld, 2004). Amazon was ranked as the No. 1 businessto-consumer retailer in the U.S. and Canada, "based on online sales, including retail chains, catalogers, web-only merchants, brand manufacturers and digital content sellers" (Enright, 2012). As a result, we determined that a $\$ 10$ Amazon gift voucher for each participant would be the most effective incentive to promote response rate.

We drew from the suggestions of numerous qualitative methodologists, as well as the data, to inform an emergent approach to data analysis. Although analysis often draws on the researcher's past experiences (LeCompte \& Schensul, 1999a), we intentionally set out to make the comparisons, category constructions, and interpretations explicit and grounded in the best available analytical techniques appropriate for this study. We interpreted through a process of dissecting, dividing, and reassembling data into understandable forms (LeCompte \& Schensul, 1999b), first collecting and summarizing all questionnaire data, then disaggregating data by themes and reassembling within categories.

We read through all questionnaire responses and coded for emergent themes. The analysis led to a recurring comparison of incidents and inductively conceived categories (Merriam, 2001). For example, emergent themes of cultural awareness, viewing education through a different perspective, having an interest in global teaching, and relating to students from diverse backgrounds all led to a tentative category of professionally-related cross-cultural awareness. Finally, we placed our categories and themes into meaningful sequences that organized the sections of our findings in response to the research questions (Glesne, 2005). These a posteriori categories informed and organized theme production and captured related questionnaire responses. As it developed and became more refined, this process of data reduction into manageable forms and reassembled data enabled interpretations (LeCompte \& Schensul, 1999b).

\section{Findings}

Of the long-term impacts of "Comparing U.S. and European Schools" (EDT455) reported by former students, perhaps the most immediate and salient concerned their job search. Over 50 respondents indicated that the course experience helped them to "stand out during the interview" and "obtain my current job." Many indicated the course led to "getting a job" and that the experience was brought up in "almost every interview." As a "résumé talking point," students determined that this was a "very appealing experience to prospective employers" and it "set me apart from other candidates 
for the teaching positions I applied for (and got)." In addition to securing employment, the course had an impact on how the students taught, in terms of reflective practices and cross-cultural awareness, as well as their personal lives. As such, we have organized the findings in terms of these three categories.

\section{Reflective Practices}

Students ( $n=73$ ) reported that the course helped them to become more open-minded as teachers. One second-year female teacher who took the course in 2006 reported that it "made me think about how European education is handled and run compared to U.S. education. It opened my eyes to the culture and student life of kids abroad compared to my own experiences . . . it made me more openminded about the direction education can and should go." A first year teacher who took the class in 2007 felt this open-mindedness translates into "relating better to my students - in my city, we have a variety of cultures and religions and I am more open and wanting to know more about my students." Another first year teacher who took the course in 2007 now teaches at a high school that is homogeneously Hispanic. She felt that "having seen how other countries educate their students was useful - that travel and experience of things different from my way of life was very beneficial" for her new position. A seventh year teacher who took the course in 2005 indicated that the course "opened my eyes to various ways of teaching and learning, allowing me to consider multiple strategies for teaching, especially when I was struggling to teach a particular piece of the curriculum or was challenged with a high needs group of students. I learned the importance and influence of culture and how it impacts learning."

Open-mindedness is a necessary condition for reflective thinking and problem solving, ideas 29 students referenced. A first year teacher who took the class in 2011 described how she indicated to her administration her willingness to work on some of the larger issues of her school district and due to the course she had "an open mind and was interested in how to make our schools the best they can possibly be." A third year teacher who took the course in 2009 reported that she "learned to question why certain things are done in education and to search for possible solutions ... the course helped me better understand different cultures, which has benefited my teaching in a social studies classroom." Another third year teacher from the 2009 class indicated that the course "helped me look at education differently and understand that there is no 'right way' to teach children. It has opened my mind to the idea that things can be done differently." A second year teacher who took the course in 2006 reflected on how the course "impacted me professionally by encouraging me to think outside the box and problem solve from a different perspective."

Students also reported that the course helped shape their teaching philosophy ( $\mathrm{n}=38)$. An eighth year teacher who took the course in 2003 suggested the course "expanded my beliefs about education" and "has been most beneficial for my curricular decision-making." In particular, this student pointed to the attentiveness she has for ESOL (English for Speakers of Other Languages) students and how she "is always planning, instructing, and assessing with these kids in mind." A fourth year teacher who took the course in 2006 reflected on the course frequently "comes up in both curricular conversations with fellow teachers and also in educational conversations with my students." In "pedagogical conversations about looping teachers, vocational education, and tracking have come up countless times-each time I've found everything relates back to cultural expectations and societal norms." A first year teacher who took the course in 2009 indicated the course "greatly impacted my teaching 
philosophy" and a teacher in her twelfth year, who took the course in 2000, felt the course "shaped my philosophy of teaching by giving me the knowledge necessary to run a classroom, communicate with parents, and prioritize what is most important in the lives of children." Finally, a third year teacher who took the course in 2009 suggested that the course "made me re-think my entire teaching philosophy. It allowed me to see how differently things are done in Europe and, in some regards, how things are done better. Although I don't get to make many curricular choices, I try to narrate as much as I can about what I'm doing. This is something I remember in the younger classrooms I saw in Europe."

Students $(n=28)$ also remarked that the course had a sustaining impact on their reflection upon teaching and learning. A second year teacher who took the course in 2009 felt that having a "better understanding of both educational systems" helped her to "use that knowledge to reflect upon my own teaching decisions." Another former student, who took the course in 2002, noted that "in creating lessons and determining how to best teach my students as well as manage the challenges and complexities of the social world, I often reflect on the themes we learned in the course-that education is a microcosm of culture and that there is an educational path for all children. These ideas have helped me better understand my role as a teacher." A former student who took the course in 2004 felt it "gave me a solid background on education and helped frame my perspective, which has helped me develop a well-rounded view of education." A student from 2005 noted that "traveling abroad and gaining insights into the history, philosophy, and method of education in other countries made me very reflective of the system we have in the United States." In addition, she felt that the "course enabled me to examine how education is a vivid reflection of cultural values." A student from 2000 noted that "during my 12 years as a teacher I have been able to reflect upon what I learned during the course. One major different I found is that in European school there are other options besides 'college bound' . . . over the years I have used this to advocate for other pathways for students in the school system in which I work." Finally, a 2008 student commented on how her exposure to a different student population and teaching methods in Europe made her "more reflective of my own teaching style and to make my lessons more student-centered."

\section{Cross-Cultural Awareness}

We found cultural consciousness to be a useful category and 40 students referenced it specifically. For example, a student from 2010 in her first year of teaching felt she was "more culturally conscious" as she tries to "provide students with materials that range in cultural topic and perspective." A student from 2008 remarked that the course "opened my eyes to the different school cultures." Another 2008 student felt the class "gave me perspective and understanding on American schools and why they run as they do." Others, including a student from 2005, felt the course contributed to her "consideration of cultural and familial perspectives" which enables her to "relate to students more successfully." Similarly, a 2006 student remarked on her increased "understanding of students" and colleagues' varied backgrounds and levels of knowledge ". . . the course helped me to be more open and understanding of culture." Ultimately this leads to, as a 2005 student remarked, an increased "ability to see different perspectives." Finally, a 2003 student remarked that the course provided her with a "wider world view and I think I tend to have a more open mind to new ideas because of it." An increased world view is related to the decreased objectivity and a shift toward framing things as "here's how we view it, here's how they view it, here's how others view it" and it "helps me teach students to better appreciate other cultural viewpoints." 
Related to cultural consciousness is the capacity to recognize and appreciate other views, perspectives, and cultural lenses. The course ultimately sought to undermine American exceptionalism and rigid normative views, which is best cinched together within the theme of perspective taking, which 51 students referenced. For example, a student from 2008 who teaches sixth grade noted how she "tries to include various resources from multiple viewpoints. I also use my experiences from the school s in Europe to help my students develop open-mindedness." A fifth grade teacher who took the course in 2010 aims to "challenge students by questioning their perspectives as being "right" and "offer students situations where they need to explain to me how that situation or experience might change their perspective. I ask students to wonder and describe how they think differing perspectives may cause challenges, conflict, and class divisions." A high school teacher who took the course in 2004 felt he was very successful teaching "AP Human Geography by getting the students to think from a global perspective. I attribute that to the experience of visiting those European schools." A kindergarten teacher who took the course in 2007 suggested the course "helped make me a globalminded teacher. I incorporate more multicultural resources in my room then I did when I was in my field experiences and student teaching." Likewise, a fourth grade teacher who took the course in 2003 pointed to the global perspective she gained from the course, which has "made me sensitive to different points of view ... I try to find many different types of literature that show alternative perspectives so my students understand how explorers, for example, we are not always the 'good guys'... I'm not sure that I would have been as sensitive to cultural diversity as early in my career if I hadn't been involved in this course.”

Within the category of cross-cultural awareness, students also reported a greater interest in global teaching, developing global citizenship, student-centered approaches, and greater appreciation of the student role in the classroom. In addition, students indicated the importance they placed on establishing rapport and trust, hands-on learning, and encourage student ownership of the curriculum. In short, students reported many of the attributes consistent with Hanvey's (1982) attainable global perspective, in terms of perspective consciousness and cross-cultural awareness.

\section{Personal Effects}

The third and final category concerns the impact of the course on student's personal lives. Students $(n=40)$ remarked on the confidence they gained as a result of the course. For example, a student from 2009 suggested that her "confidence to travel independently in the US has increased because I traveled to countries where English was not the native language. I also feel more confident to share my opinion about education given the experience." A student from 2007 who teaches kindergarten suggested she is "much more comfortable talking with others about the pros and cons about education in the US" and a student from 2011 became "much more independent and selfsufficient as a result of my experience in Europe. It taught me not only about interacting with different people, but developed my 'street smarts' and inspired me to travel more." A third grade teacher who took the course in 2005 attributed the experience to helping her "speak up during faculty and districtlevel meetings regarding curricular decision making, teacher evaluation systems, special education meetings, as well as others." Finally, a first year teacher who took the course in 2010 remarked on how the course "impacted my confidence level when going into interviews. It's really nice to know that I've compared and contrasted best practices of American and European education ... I feel as though I have a thorough knowledge base which helps as a beginning teacher." 
Confidence is also related to a desire to travel more and make traveling a "life priority." Over 90 students made comments of this ilk, including "the course increased my love for travel" and "I fell in love with international travel as a result of this trip. I feel I grew as a person and an educator as a result of this experience." A 2006 student noted that she is "much more likely to travel and keep in mind what is happening not only in Europe, but across the globe, especially in education, and bring that back to my school." Another 2006 student suggested that since that course she "loves traveling to various areas and learning more about local cultures." Given the nature of the course, whereby students are not simply tourists but engaged in inquiry to understand education in a different culture, many of their travel desires for the future are not simply to travel, but, as a student from the 2001 course suggested, "talk with locals and get an inside view of the other countries. I think it is also important to travel with family and expose my children to other cultures and how they differ from the US." A student from 2010 indicated that she would "like to travel both domestically and internationally more as the trip fostered an appreciation for getting to know the local life and lifestyle of places I have not known." Finally, a 2004 graduate spoke about his continuing travel and since the course has visited Brazil, Egypt, Costa Rica, and Puerto Rico. He "continually keeps up on international politics, foreign policy, and cultural issues. I think the greatest part of that course was motivating me to seek other opportunities to travel and seek out conversations with foreigners in the US to ask questions about their perspectives on the US, foreign issues, and cultural norms within their country."

In our analysis of the responses from 148 former students of the comparative education class who later became teachers, multiple benefits of the short-term study abroad experience were cited. One immediate impact related to us was a perception by many of the respondents that this experience provided them with an advantage during the job interview process over those candidates that had no such similar experiences, several other areas of focus emerged from our analysis. The respondents also noted an impact in their teaching practices in the area of enhanced reflective practice and a heightened sensitivity to cross-cultural issues and teaching. Finally, most respondents indicated some degree of personal growth in confidence, both in regard to their own travel and to their selfassurance in speaking to others about professional and global-related issues. We will expound on each of these briefly in the following section.

\section{Discussion and Conclusion}

The questionnaire used for this study was open-ended and designed to elicit general comments as to whether or not current teachers who had taken a short-term comparative education course as part of their undergraduate teacher preparation program believed this experience had influenced them and their teaching. Some of the respondents took the course as many as twelve years earlier and the response rate of $46 \%$ was substantially higher than the average of $30 \%$ for web-based constructed surveys (Hamilton, 2003). In analyzing the data, it became apparent that most of the respondents viewed this short-term experience as impactful both professionally and personally. As a result, this study suggests that carefully constructed, short-term study abroad experiences can indeed have a lasting impact on teacher candidates. Specifically, several themes emerged regarding the particular benefits of this short-term study abroad experience.

The first of these was that many of the respondents believed that the study abroad experience had given them an advantage during a job interview. The initial purpose of this study was not to determine if a study abroad experience taken during one's undergraduate teacher preparation program 
enhanced the chances of obtaining a teaching job. The responses we received however indicated that a sizable proportion of those who participated in the program believed it did give them a "leg up" in this process. This finding is consistent with a study (Shiveley \& Misco, 2012) which indicated that administrators from a Midwestern state who hired teachers believed that, all other variables being equal, a preservice teacher with study abroad experience seeking employment in their district was more highly regarded than those who did not have such an experience.

Second, respondents commented on how the educationally-focused study abroad experience caused them to be more reflective of their own educational practices, prompting them to be more open-minded, develop a better understanding of the U.S. educational system, and view education more as a reflection of the culture in which it is housed. Several respondents commented on how this experience caused them to rethink their own teaching philosophy in a way that included a wider and more rounded view of education.

Finally, respondents' reported that this experience caused them to increase their own level of cross-cultural awareness. Related comments include having a greater appreciation for multiple perspectives, a greater sense of cultural sensitivity, and an enhanced understanding of various school cultures. Many respondents indicated that this change in cross-cultural awareness had a tangible impact on their own classroom practice, giving examples such as selecting more multiculturally-oriented teaching materials and resources, promoting more ambiguity in their classroom discussions, encouraging more student ownership in the learning process, and infusing a concept of global citizenship into their teaching practice.

Finally, most respondents mentioned that, beyond professional growth and classroom practice, one of the largest areas of change was in the area of personal growth. Time and again comments were made on how this experience gave them more confidence in general and an increased perception of self-sufficiency. Many expressed a greater confidence to travel on their own to places they did not believe they previously would have gone to on their own. This increased confidence level not only impacted their personal travel plans, but also spilled over into conversations with peers about international issues and educational practice. We believe this personal growth is significant in that, while not directly impacting classroom practice, does influence the teacher as a person and thus indirectly affects the teaching that occurs in the classroom.

The conclusions we reach in study are based solely on teachers self-reporting on what they believe the impact of a short-term study abroad experience taken years earlier had on them as individuals and professionals. No classroom data was collected or observations were made. There is no way to determine whether or not the changes claimed by the respondents are truly manifested in classroom practice and decision making, nor is there any way to determine to what extent such changes are the direct result of this particular study-abroad class or are a result of a culmination of events that may have occurred since that first experience. What we do suggest is that 148 students who took a short-term study abroad experience and then went on to teach were able to articulate multiple ways in which they believe this experience increased their marketability, reflective practice, cross-cultural awareness, and personal confidence.

There exists an increasing awareness that globally competent teachers are needed in today's classrooms and that universities preparing teachers need to do more to infuse such competencies into 
their programs. It is also understood that a key component is direct, first-hand contact with people and institutions from other countries. Highly structured contextual teacher preparation programs have little room to include study abroad trips and, when room is carved out, these trips tend to be of short duration. This study provides evidence that structured, short-term study abroad experiences for preservice teachers can have some of the desired globally-oriented outcomes called for in the literature.

\section{References}

Achterberg, C. (2002) Providing a global perspective: An educator's duty. About Campus, 6(6), 17-22.

Asia Society. (2010) State Initiatives on Global Learning. Retrieved from http://asiasociety.org/node/20794.

Blair, J. (2002) College sending teacher-candidates to see the world. Education Week, $\quad 22(15), 8$.

Centers for Disease Control and Prevention (CDC). (2010). Increasing Questionnaire Response Rates. Evaluation $\quad$ Brief, 21, 1-2. Retrieved from http://www.cdc.gov/HealthyYouth/evaluation/pdf/brief21.pdf

Chapman, J., Becker, J., Gilliom, M. E., \& Tucker, J. (1982). NCSS position statement on global education. Social Education, 46, 36-38.

Cole, C., Palmer, R., \& Schwanz, D. (1997). Improving the mail return rates of SASS surveys: A review of the literature. Suitland, MD: Bureau of the Census. ERIC Ref. ED 416248.

Cox, T. (1993) Cultural diversity in organizations: Theory, research, and practice. San Francisco, $\quad$ CA: Berrett-Koehler.

Deng, S., \& Boatler, R. W. (1993). Worldmindedness among Canadian business students: Implications for curricula. Journal of Education for Business, 69(2), 94-98.

Dillman, D. A. (1991). The design and administration of mail surveys. Annual Review of Sociology, 17, 225-249.

Douglas, C., \& Jones-Rikkers, C. (2001) Study abroad programs and American student worldmindedness: An empirical analysis. Journal of Teaching in International Business, 13(1), 55-66.

Dwyer, M. M. (2004). More is better: The impact of study abroad program duration. Frontiers: The Interdisciplinary Journal of Study Abroad, 10, 151-164.

Enright, A. (2012). Amazon leads major e-retailers in a customer satisfaction survey. Top 500 U.S. ERetailers. Retrieved, from http://www.internetretailer.com/2012/11/29/amazon-leads-major-eretailers-customer-satisfaction-survey

Fox, R., Crask, M., \& Kim, J. (1988). Mail survey response rate: A meta-analysis of selected Techniques for inducing response. Public Opinion Quarterly, 52(4), 467-

Glesne, C. (2005). Becoming qualitative researchers. White Plains, NY: Longman.

Hamilton, M. (2003). Online survey response rates and times: Background and guidance for industry. Tercent Inc. Retrieved from http://www.utexas.edu/academic/ctl/assessment/iar/teaching/gather/method/surveyResponse.php?task=programs

Hanvey, R. G. (1982). An attainable global perspective. Theory into practice,21(3), 162-167.

Hartman, D., \& Rola, G. (2000) Going global with service learning. Metropolitan Universities, 11(1), 15-23.

Hett, E. J. (1993). The development of an instrument to measure global-mindedness. Unpublished doctoral dissertation, University of San Diego. UMI Dissertations 9408210.

Hopkins, J. (1999) Studying abroad as a form of experiential education. Liberal Education, 85(3), 36-41. 
Kehl, J. \& Moris, J. (2008). Differences in global -mindedness between short-term and semester-long study abroad participants at selected private universities. Frontiers: The Interdisciplinary Journal of Study Abroad, 15, 67-79.

Kitsantas, A., \& Meyers, J. (2001) Studying abroad: Does it enhance college students cross cultural awareness? Paper presented at the combined Annual Meeting of the San Diego State University and the U.S. Department of Education Centers for International Business Education and Research, San Diego, CA. Retrieved http://www.eric.ed.gov/ERICWebPortal/search/detailmini.jsp?_nfpb=true\&_\&ERICExtSearc h_SearchValue_0=ED456648\&ERICExtSearch_SearchType_0=no\&accno=ED456648

Laubscher, M. (1994) Encounters with a difference: Students with perceptions of the role of out-of-class experiences in education abroad. Westport, CT: Greenwood Press

LeCompte, M. D. \& Schensul, J. J. (1999a). Designing and conducting ethnographic research. Walnut Creek, CA: AltaMira.

LeCompte, M. D. \& Schensul, J. J. (1999b). Analyzing \& Interpreting ethnographic data. Walnut Creek, CA: AltaMira.

Levy, D. (2000) The shock of the strange, the shock of the familiar: Learning from study abroad. Study of National Collegiate Honors Council, 1(1), 75-83.

Longview Report (2009). Teacher preparation for a global age: The imperative for change. http://www.longviewfdn.org/files/44.pdf

Malewski, E., \& Phillion, J. (2009). International field experiences: The impact of class, gender, and race on the perceptions and experiences of preservice teachers. Teaching and Teacher Education, 25, $52-60$.

Maxwell, J. A. (2010). Using numbers in qualitative research. Qualitative Inquiry, 16(6), 475-482.

McKay, J. W., \& Montgomery, J. (1995). Changes in perceptions: A comparative study of the experiential learning of international student teachers. A paper presented at the Annual Meeting of the American Educational Research Association, San Francisco, CA.

Medina-López-Portillo, A. (2004). Intercultural Learning Assessment: The Link between Program Duration and the Development of Intercultural Sensitivity. Frontiers: The Interdisciplinary Journal of Study Abroad, 10, 179-199

Merriam, S. B. (2001). Qualitative research and case study applications in education. San Francisco, CA: JosseyBass.

Merryfield, M. (1994) Teacher education global and international education.

Washington, DC: AACTE Publications.

Miles, M. B. \& Huberman, A. M. (1994). Qualitative data analysis. Thousand Oaks, CA: Sage.

Moseley, C., Reeder, S., \& Armstrong, N. (2008). "I don't eat white": The transformational nature of student teaching abroad. Curriculum \& Teaching Dialogue, 10(1/2), 55-71.

Patton, M. Q. (1990). Qualitative evaluation and research methods. Newbury Park, CA: Sage.

Pence, H. M., \& Macgillivray, I. K. (2008). The impact of an international field experience on preservice teachers. Teaching and Teacher Education, 24, 14-25.

Quezada, R. L. (2004) Beyond Educational Tourism: Lessons Learned While Student Teaching Abroad. International Education Journal, 5(4), 458-465.

Quinn, L. F., Barr, H., Jarchow, E., Powell, R., \& McKay, W. J. (1995) International student teaching: New Zealand and the United States perspectives on schooling. Action in Teacher Education, 12(3), 13-21.

Ruyter, K. D., Wetzels, M., \& Oosterveld, P. (2004). Response Rate and Response Quality of InternetBased Surveys: An Experimental Study. Marketing Letters, 15(1), 21-36. 
Sharma, M. P. \& Klasek, C. B. (1986). Does the involvement of American institutions of higher education in international programs abroad affect the international attitudes of American students? Journal of Studies in Technical Careers, 8(4), 295-305.

Shiveley J. M., \& Misco, T. (2012). Student teaching abroad will help you get a job: Exploring administrator perceptions of international experiences for preservice teachers. The International Education Journal: Comparative Perspectives, 11(1), 52-68.

Slavin, R. E. (1992). Research methods in education. Boston, MA: Allyn and Bacon.

Stachowski, L. L. (2001). Enhancing international student teaching experiences. Education, 112(3), 347 351.

Stephenson, S. (1999) Study abroad as a transformational experience and its effects upon Study abroad students and host nationals in Santiago, Chile. Frontiers: The Interdisciplinary Journal of Study Abroad, 5, 1-38.

Toma, J. D. (2006). Approaching rigor in applied qualitative research. In C. F. Conrad \& R. C. Serlin (Eds.), The Sage handbook for research in education. Thousand Oaks, CA: Sage.

Trooboff, S., Vande Berg M., \& Rayman, J. (2007-2008) Employer attitudes toward study abroad. Frontiers: The Interdisciplinary Journal of Study Abroad, 15, 17-33.

Willard-Holt, C. (2001). The impact of a short-term international experience for preservice teachers. Teaching and Teacher Education, 17, 505-517.

Wilson, A. H. (1982). Cross-cultural experiential learning for teachers. Theory Into Practice, 21(3), 184192.

Wilson, A. H. (1993). Conversations partners: Helping students gain a global perspective through cross-cultural experiences. Theory Into Practice, 32(1), 21-26.

Yammarino, F. J., Skinner, S. J., \& Childers, T. L. (1991). Understanding mail survey response behavior: a meta-analysis. Public Opinion Quarterly, 55(4), 613-639.

Zhai, L. \& Scheer, S. D. (2004). Global perspectives and attitudes toward cultural diversity among summer agricultural students at the Ohio State University. Journal of Agricultural Education, 45(2), $39-51$.

Zorn, C. R. (1996) The long-term impact on nursing students of participating in international education. Journal of Professional Nursing, 12(2), 106-110. 
Appendix A - Survey Questions

What is your name?

Since graduation from Miami University, have you been employed as a teacher?

Are you currently employed as a teacher?

In which summer did you take Comparing U.S. and European Schools at Miami University?

What is your current position?

Where do you currently work?

In which city and state do you currently live?

What is your age?

How many years have you been employed in your current position?

What is your gender?

What is your email address?

Would you be willing to answer additional follow-up questions by phone or email?

In as much detail possible, please describe how Comparing U.S. and European schools has impacted you professionally.

If you are teaching, to what extent has this course impacted your pedagogical and curricular decisions (e.g., global perspectives of content, resource selection, questioning district or state educational policies, etc.)?

In as much detail as possible, please describe how Comparing U.S. and European schools has impacted you personally (e.g., more likely to travel internationally, more likely to travel domestically, more likely to read articles, books, or blogs about Europe, more likely to discuss European issues or travel with friends and colleagues, etc.).

Students of this course often remark that neither U.S. nor European schools are ideal and that both systems can learn from each other. For example, students have suggested that levels of inclusion, trust, technology, language, classroom management, tracking, diversity, and extracurricular activities are qualitatively different by comparison. To what extent do you believe this to be the case? To what extent have you modified your classroom or your school's policies given your knowledge of these differences? 